\title{
Endovascular treatment of a ruptured abdominal aortic aneursym in a patient with cardiogenic shock
}

\author{
Ali Baran Budak ${ }^{1}$, Atike Tekeli Kunt ${ }^{2}$, Orhan Eren Günertem², Naim Boran Tümer ${ }^{2}$, \\ Kanat Özışık ${ }^{3}$, Serdar Günaydın ${ }^{3}$
}

1) Ankara Numune Education and Research Hospital, Cardiovascular Surgery Department, Exp. Dr., Ankara, Turkey

2) Ankara Numune Education and Research Hospital, Cardiovascular Surgery Department, Assist. Dr., Ankara, Turkey

3) Ankara Numune Education and Research Hospital, Cardiovascular Surgery Department, Prof. Dr., Ankara, Turkey

\begin{abstract}
Abdominal aort aneurysm is an asymptomatic and potentially lethal disease which its rupture is an emergent situation. In many centers, patients presenting with ruptured abdominal aortic aneurysm (rAAA) are most often treated with open repair(OR). A 55-year-old male with acute abdominal pain admitted to our hospital. Computed tomography scan showed a rAAA. A sudden cardiac arrest occured. The patient immediately transferred to catheter laboratory with cardiogenic shock table and endovascular treatment was performed. Then he was discharged in the postoperative 7 th day.
\end{abstract}

Keyword: ruptured abdominal aort aneursym, endovascular repair, cardiogenic shock 


\section{Introduction}

Abdominal aort aneurysm is an asymptomatic and potentially lethal disease which its rupture is an emergent situation and has a fatality rate of $100 \%$ if untreated. Misdiagnosis causes delays for the treatment and it can be catastrophic. Depending on the patient's status during admission, the mortality ranges from $20 \%$ to $70 \%$ even in treated patients. ${ }^{[1,2]}$ In many centers, patients presenting with ruptured abdominal aortic aneurysm (rAAA) are most often treated with open repair(OR). But in centers whom have a hybrid operating room as the surgeons' comfort and confidence with the technique increases, ruptured endovascular aneurysm repair (rEVAR) has become the preferred treatment option. Furthermore, patients with rAAA who are transferred for a higher level of care have superior clinical outcomes when treated with rEVAR, compared with OR ${ }^{[3]}$ Herein, we aimed to demonstrate the feasibility of emergent rEVAR in a patient with cardiogenic shock who underwent succesful resuscitations after three times caridac arrest.

\section{Case Report}

A 55-year-old male with acute abdominal pain was transferred to our emergency department and took under evaluation of general surgery and urology clinics with suspicious of renal colic and ileus. At the presen-

Figure 1. 3D CT Image. Aneurysm extends from the distal of SMA and includes the renal arteries

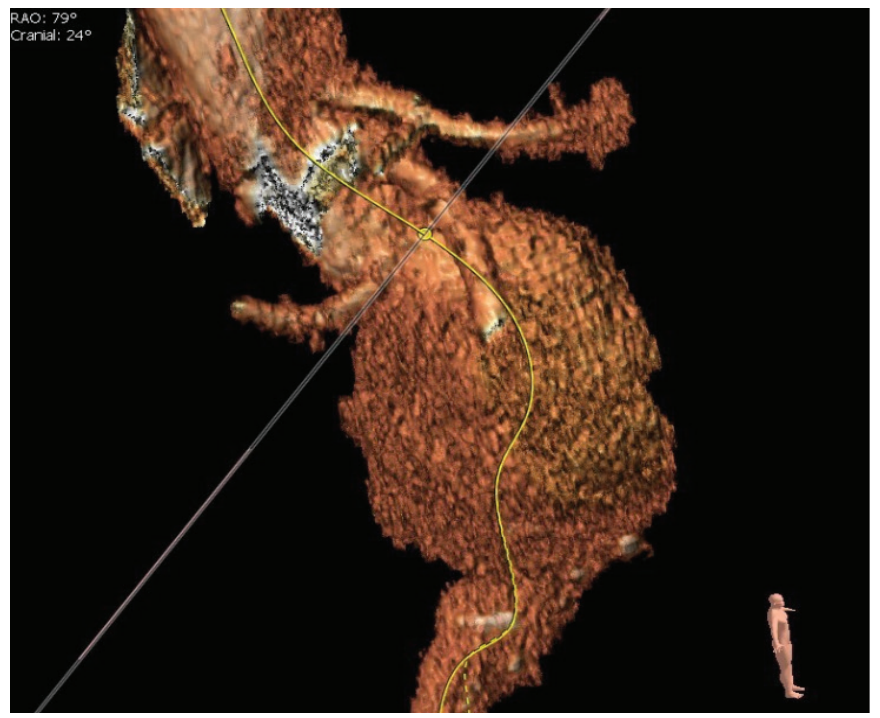

tation, serum urea level was $80 \mathrm{mg} / \mathrm{dl}$, creatinin level was $2.97 \mathrm{mg} / \mathrm{dl}$ and hemoglobin level was $7.5 \mathrm{~g} / \mathrm{dl}$. Computed tomography scan showed a rAAA extending from the caudal of superior mesenteric artery (SMA) to aortic bifurcation with a diameter of $8.53 \mathrm{~cm}$. The aneurysmal sac included the right renal artery, but left renal artery could not be demonstrated (Figure 1). The measurements of the aneurysm is shown in Table 1. The level of the rupture is shown in Figure 2.

After computed tomographic assessment, a sudden cardiac arrest occured. The patient was entubated and an immediate resuscitation procedure was performed. Systolic blood pressure could be increased to $40 \mathrm{mmHg}$ and caridac arrest repeated for 3 times. After the systolic blood pressure was secured around $50 \mathrm{mmHg}$, the patient immediately transferred to catheter laboratory for endovascular repair. Bilateral surgical cutdown to the groin was performed. after positioning a $20 \mathrm{~F}$ sheat

Table 1. The measurements of the aneurysm.

\begin{tabular}{|l|c|}
\hline Measured Area & Milimeter \\
\hline Proximal diameter of neck & 30.3 \\
\hline Distal diameter of neck & 28 \\
\hline Neck length & 12 \\
\hline Max aneurysm diameter & 85.3 \\
\hline Distal aorta diameter & 22.5 \\
\hline SMA to distal aorta & 142.4 \\
\hline Proximal diameter of RCI & 13 \\
\hline Diameter of RCI & 14.5 \\
\hline Distal diameter of RCI & 18.2 \\
\hline Length of RCl & 73.2 \\
\hline Total length from right (SMA to & 215.7 \\
\hline right internal iliac artery) & \\
\hline Proximal diameter of LCl & 12 \\
\hline LCl diameter & 13.5 \\
\hline Distal diameter of LCl & 16.9 \\
\hline Length of LCl & 76.8 \\
\hline Total length from left (Infra renal & 219.2 \\
\hline level to left internal iliac artery & \\
\hline
\end{tabular}


to left CFA (Sentrant Sheath, Medtronic), a uniiliac

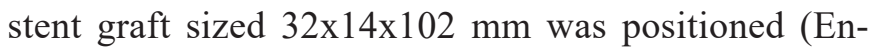
durant ${ }^{\circledR}$ II uniiliac, Medtronic). SMA was preserved. After succesful positioning of the graft, a 16x20x156 $\mathrm{mm}$ stent graft (Endurant ${ }^{\circledR}$ II, Medtronic) was used for the extension to the left iliac artery. Particular attention was paid to keep the left internal iliac artery open. During the procedure, cannulation of the contralateral limb was unable to be achieved because of the tortuous aortoiliac course. Since the patient was unstable, the Endurant system was combined with Talent ${ }^{\circledR}$ Converter stent-graft occluder $(20 \mathrm{~mm}$, Medtronic, Inc.; Minneapolis, Minn) positioned to right common iliac artery via a $18.5 \mathrm{~F}$ introducer sheath. An aortography was made and a minimal leak from the overlap area was observed. Upon this, Reliant ${ }^{\circledR}$ (Medtronic, Inc.; Minneapolis, Minn) baloon catheter was used to expand the stent graft and reinforce the overlap zone. After the closure of the rAAA was confirmed.(Figure 3) Additional left-to-right femorofemoral bypass with a $8 \mathrm{~mm}$ Gore-Tex graft was performed. After succesful closure of the rAAA, the patient was taken to the intensive care unit. Postprocedural hemoglobin was $9.8 \mathrm{~g} /$ $\mathrm{dl}$, serum creatinin level was $3.63 \mathrm{mg} / \mathrm{dl}$. The patient was extubated $32 \mathrm{~h}$ after the procedure without neuro- logic dysfunction. Renal failure was expected and the patient was consulted to the nephrology clinic for routine dialysis program. The patient was discharged in the postoperative 7 th day.

\section{Discussion}

rAAA is a catastrophic condition and the role of rEVAR is still controversial due to the absence of wellsupported evidences. Mortality is higher after OR than EVAR according to retrospective studies ${ }^{[4-7]}$ and confirmed by the Swedish Vascular Registry. ${ }^{[8]}$ Furthermore, preoperative shock table and unstable status was found as a major factor predicting mortality rate ${ }^{[9]}$ Also many publications pointed out that the duration of intensive care is shorter ${ }^{[10,11]}$ and operative blood loss and/ or need for transfusion is lowerin rEVAR patients. ${ }^{[12,13]}$ Our patient was followe up for 5 days in ICU and we only gave 2 units of erythrocyte suspension and 2 units of fresh frozen plasma during the operation. Since rEVAR allows the reduction of intraoperative blood loss and the elimination of the aortic clamping and fluid shifts/losses due to a large transperitoneal incision, we did not encountered with a cardiac complication. After overlapping the stent grafts, we observed a type III

Figure 2. Computed-Tomography Scan. Level of rupture was seen.
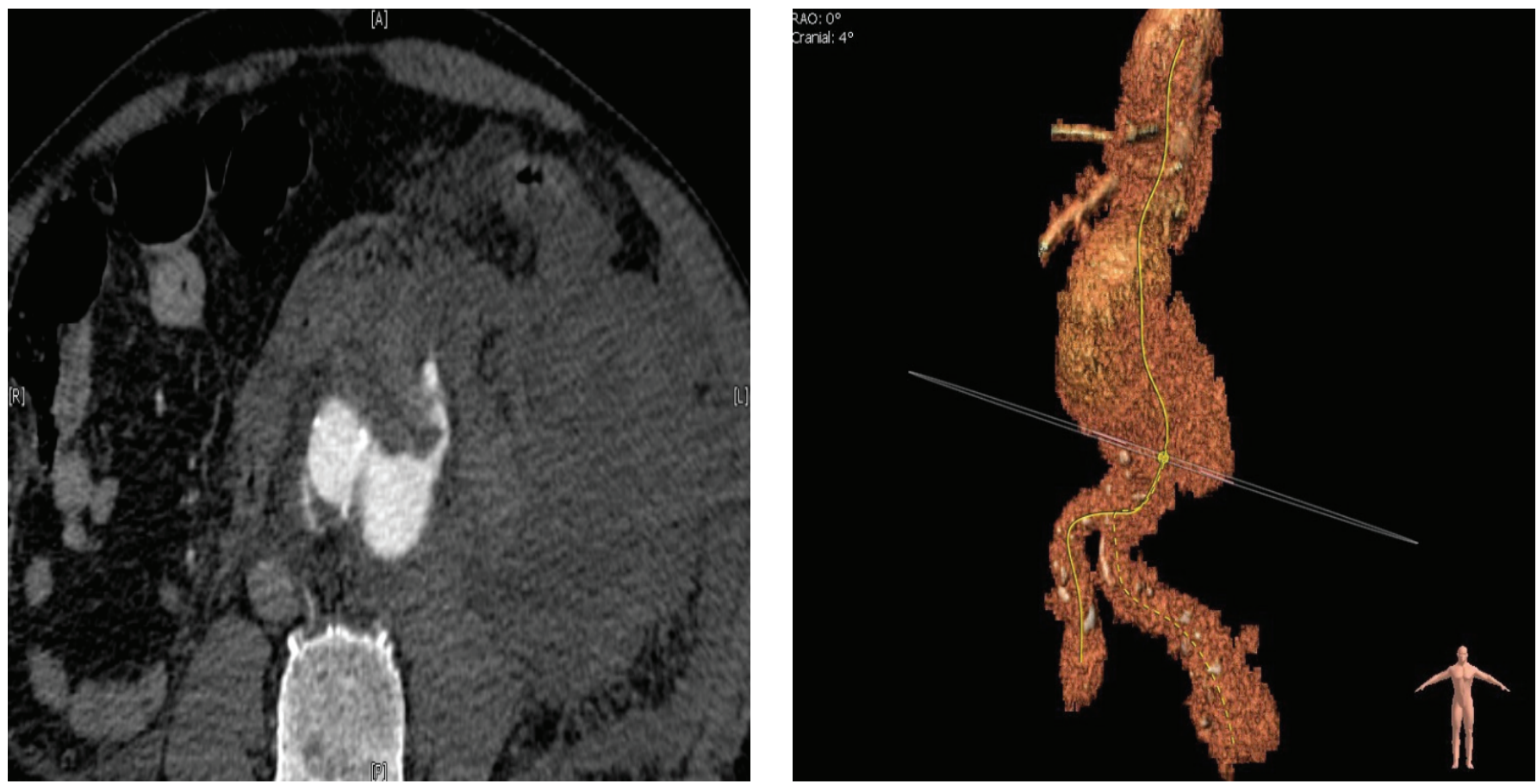
endoleak from the overlap zone then we fixed it by using a balloon catheter. We also placed an occluder to right common iliac artery to prevent a type II endoleak , as mentioned above. Immediate resuscitation in the emergency department, succesful management of a comatose and unstable patient both in the preoperative

\section{Figure 3. Angiographic Image. Succesful closure of} the rAAA was seen.

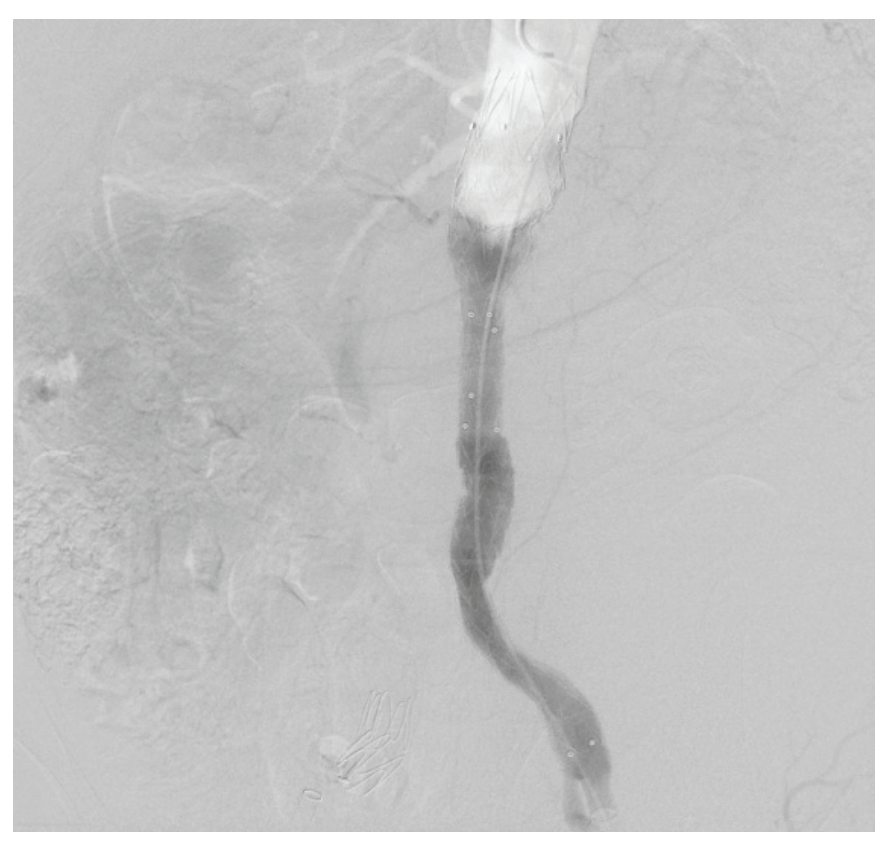

and postoperative period protected the patient to have a neurological complication.

Our first goal was to achieve a safe transfer to the intensive care unit and keep patient alive. Due to lack of every size and types of graft in our hospital and inability to perform a contralateral limb cannulation we had to admit renal complications and ischemia risk of contralateral limb. Femorofemoral bypass surgery prevented ischemic complications but renail failure was occured and the patient became dialysis dependent. On the other hand renal artery occlusion is also a well known complication of EVAR and it can occur by several mechanism. ${ }^{[14-16]}$

In this case report we aimed to demonstrate the feasibility of emergent rEVAR in a patient with cardiogenic shock and help cardiovascular surgeons for the future. In a this kind of emergent status chosing the treatment modality (open surgery whether endovascular repair) is debatable. Our another goal was to enrich the literature about this kind of medical scenarios . Further studies and long-term results of endovascular procedures in patients with ruptured aort aneursym are still needed. 


\section{References}

1. LarssonE,GranathF,SwedenborgJetal(2008)Morepatientsare treated for nonruptured abdominal aortic aneurysms, but the pro- portion of women remains unchanged. J Vasc Surg 48(4):802-807

2. Ozdemir BA, Karthikesalingam A, Sinha S et al (2015) Associ- ation of hospital structures with mortality from ruptured abdominal aortic aneurysm. Br J Surg 102(5):516-524

3. Mandawat A, Mandawat A, Sosa JA, Muhs BE, Indes JE. En- dovascular repair is associated with superior clinical outcomes in patients transferred for treatment of ruptured abdominal aortic aneurysms. J Endovasc Ther 2012;19(1):88-95.

4. Lo RC, Bensley RP, Hamdan AD et al (2013) Gender differences in abdominal aortic aneurysm presentation, repair, and mortality in the Vascular Study Group of New England. J Vasc Surg 57(5): 1261-1268

5. Mehta M, Byrne WJ, Robinson H et al (2012) Women derive less benefit from elective endovascular aneurysm repair than men. J Vasc Surg 55(4):906-913

6. de Leur K, Flu HC, Ho GH et al (2015) Outcome of elective treatment of abdominal aortic aneurysm in elderly patients. Int J Surg 15:117-123

7. Ullery BW, Tran K, Chandra V et al (2015) Association of an endovascular-first protocol for ruptured abdominal aortic aneur- ysms with survival and discharge disposition. JAMA Surg 150(11):1058-1065

8. Swedvasc (2015) Swedvasc. Annual report from the Swedish National vascular registry. In: SSVS U (ed.) http://www.ucr.uu. se/ swedvasc/
9. Mehta M, Byrne J, Darling RC 3rd, Paty PS, Roddy SP, Krei- enberg $\mathrm{PB}$, et al. Endovascular repair of ruptured infrarenal abdominal aortic aneurysm is associated with lower 30-day mortality and better 5-year survival rates than open surgical repair. J Vasc Surg 2013;57(2):368-75.

10. Wibmer A, Schoder M, Wolff KS et al: Improved survival after abdominal aortic aneurysm rupture by offering both open and endovascular repair. Arch Surg, 2008; 143(6): 544-49; discussion 550

11. Anain PM, Anain JM Sr., Tiso M et al: Early and mid-term results of rup- tured abdominal aortic aneurysms in the endovascular era in a communi- ty hospital. J Vasc Surg, 2007; 46(5): 898-905

12. Anain PM, Anain JM Sr., Tiso M et al: Early and mid-term results of rup- tured abdominal aortic aneurysms in the endovascular era in a communi- ty hospital. J Vasc Surg, 2007; 46(5): 898-905

13. Starnes BW, Quiroga E, Hutter C et al: Management of ruptured abdominal aortic aneurysm in the endovascular era. J Vasc Surg, 2010; 51(1): 9-17; discussion 18

14. Gorich J, Rilinger N, Soldner J, et al. Endovascular repair of aortic aneurysms: treatment of complications. J Endovasc Surg 1999;6:136-14

15. Liewald F, Sharrer-Pamler R, Gorich J, et al. Intraoperative, perioperative, and late complications with endovascular therapy of aortic aneurysm. Eur J Vasc Endovasc Surg 2001; 22:251-256

16. Hausegger KA, Schedlbauer P, Deutschmann HA, Tiesenhausen K. Complications in endoluminal repair of abdominal aortic aneurysms. Eur J Radiol 2001;39:22-33

Received: 30/06/2017

Accepted: 26/08/2017

Published: 15/09/2017

\section{Disclosure and conflicts of interest:}

The authors declare no conflict of interest.

\section{Corresponding author:}

Dr. Ali Baran Budak

Mail: drbaranbudak@gmail.com 